\title{
ANOMALIA TECTÔNICA NA BACIA AMAZÔNICA DETECTADA PELO SAAS
}

\author{
J. BERROCAL*, E. A. LADEIRA** e A. FARIA**
}

\begin{abstract}
The plate tectonics theory, which explains the tectonic and physiographic aspects of the Earth, has found a good reception among contemporary geophysicists and geologists. The South American plate may be divided in two parts: the Guiamas Shield and the Brazilian Shield, separated by the Amazon basin.

The seismological station of Brasilia, with its array system (SAAS), has detected an anomaly in the amplitude of seismic events occuring to the North of the Amazon basin, and appears as a loss of energy somewhere on their wave path. Earthquakes with the same magnitude and epicentral distance, occuring in the Chilean or Peruvian Andes, show a larger amplitude at SAAS than the ones occuring in the Colombian or Venezuelan Andes. We therefore think that there is a discontinuity in the wave path of events occuring north of the Amazon basin.

The Guianas and Brazilian shields are considered by some authors as individual blocks, based mainly on the Mesozoic and Cenozoic sediments of the Amazon basin separating them, and based also on the different trend of the structural lineaments of both shields. The seismic anomaly detected by SAAS could therefore represent a deeper separation of both shields to such a depth that would cause a discontinuity in these wave paths. This therefore could represent a tectonic anomaly under the Amazon basin.
\end{abstract}

INTRODUçÃo A implantação da Estação Sismológica de Brasília (ESB), no Planalto Central Brasileiro, encontra-se atualmente em fase final de instalação. Seguindo o objetivo original para o qual foi projetada pelo Centro Regional de Sismologia para América do Sul (CERESIS), vem fornecendo dados sísmicos e novas facilidades para pesquisas. Tal acervo permite enfocar certos problemas da sismotectônica sul-americana de outro ângulo, talvez mais apropriado, e com ferramentas mais poderosas constituídas pelo sistema de arranjo SAAS (South American Array System), e seu registro em fita magnética, as quais serão complementadas satisfatoriamente após a instalação do sistema WWSSS (World Wide Standard Seismograph System).

Desde o início da etapa experimental da ESB, em novembro de 1966, notou-se a existência de uma irregularidade no registro dos sismos ocorridos ao norte da Bacia Amazônica. Somente agora foi possível investigar tal irregularidade, graças à constituição do Grupo de Geofisica do Departamento de Geociências da Universidade de Brasília, ao qual pertencem os autores, e graças ao interesse do Brasil em participar do Projeto Internacional de Goodinâmica.

O presente trabalho é somente uma apresentação da existência da anomalia sísmica e uma discussão preliminar das possíveis causas. A investigação da causa da anomalia prosseguirá integrando o programa de pesquisa apresentado pela Universidade de Brasilial para participar ao Projeto de Geodinâmica.

Para melhor se compreenderem os pontos de vista expostos neste trabalho, é conveniente apresentar antes os conceitos básicos das teorias mais aceitas na atualidade, que explicam a fisiografia atual de nosso planeta, assim como alguns tópicos de sismologia relativos aos argumentos aqui expostos.

*Instituto Geofisico do Peru e Departamento de Geociências da Universidade de Brasília **Departamento de Geociências da Universidade de Brasília 
Princípios básicos da tectônica de placas A teoria das placas continentais, ou tectônica de placas, procura explicar os processos tectônicos que se desenvolvem nos envoltórios superficiais da Terra, oferecendo um raciocínio lógico que relaciona os fenômenos tectônicos com a atual fisiografia de nosso planeta.

Essa nova teoria é uma conseqüência do fenômeno da expansão dos pisos oceânicos, que foi evidenciado por Dietz (1961) e Hess (1962) e posteriormente confirmado por muitos outros geofísicos, como, por exemplo, Sykes (1967), Morgan (1968), Le Pichon (1968), Le Pichon e Heirtzler (1968), Heirtzler e outros (1968), Pitman e Hayes (1968), Isacks e outros (1968), etc., corroborando, outrossim, a sugestão de Vine e Matthews (1963) de que a distribuição simétrica das anomalias de magnetização a partir das cadeias médio-oceânicas, foi devida à emissão contínua de magma, combinada com as variações de polaridade do campo magnético da Terra. A distribuição simétrica em forma de faixas, a partir do centro das cadeias médio-oceânicas e a diferente polarização dessas faixas proporcionam uma medida da velocidade de expansão dos pisos oceânicos que é avaliada em poucos centímetros por ano. Segundo Le Pichon (1968), alcança a cifra de 8,5 a 8,7 $\mathrm{cm} / \mathrm{ano}$.

A teoria da tectônica de placas fundamenta-se também no conceito de "falhas transformais" (transform faults), definidas por Wilson (1965) (Fig. 1).

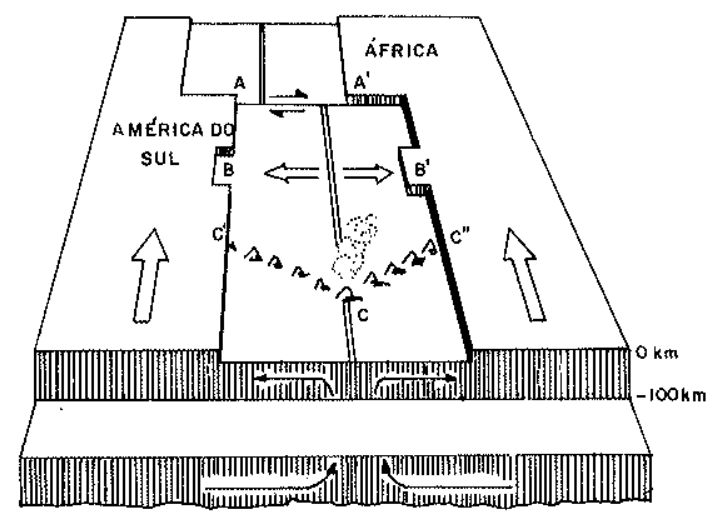

Figura 1 - Separação das placas da América do Sul e África (Dietz e Holden, 1970)

Segundo essa conceituação de placas continentais, estima-se que a Terra possua - uma litosfera de aproximadamente $100 \mathrm{~km}$ de espessura, dividida em várias placas rígidas, limitadas por fossas (trenches) e cadeias (rifts) oceânicas e por grandes fraturas de ordem continental (megashears). Um exemplo aproximado de uma placa ideal seria a placa da Índia, que tem seus bordos retilíneos e compostos por uma fossa e uma cadeia oceânica, opostas entre si, e por duas fraturas (megashears), também opostas. Aparentemente as placas acham-se distribuídas em dois sistemas, um movendo-se no sentido norte, o sistema Oceano Índico-Thétis, e o outro, o sistema Atlântico-Pacífico, movendo-se no sentido oeste.

As placas continentais rígidas, ou litosfera, movem-se sobre a astenosfera, de natureza menos rígida e com características de alta viscosidade, correspondendo à "zona de baixa velocidade" do manto superior; a astenosfera possui uma espessura de centenas de quilômetros (Isacks e outros, 1968), descansando sobre uma região rígida e possivelmente inerte do ponto de vista tectônico, designada por mesosfera. A terminologia usada na divisão das camadas superficiais da Terra foi sugerida por Daly (1940).

Na Fig. 2, mostra-se um resumo dos principais aspectos da tectônica de placas, em conformidade com o esquema que segue, sugerido por Dietz e Holden (1970). 


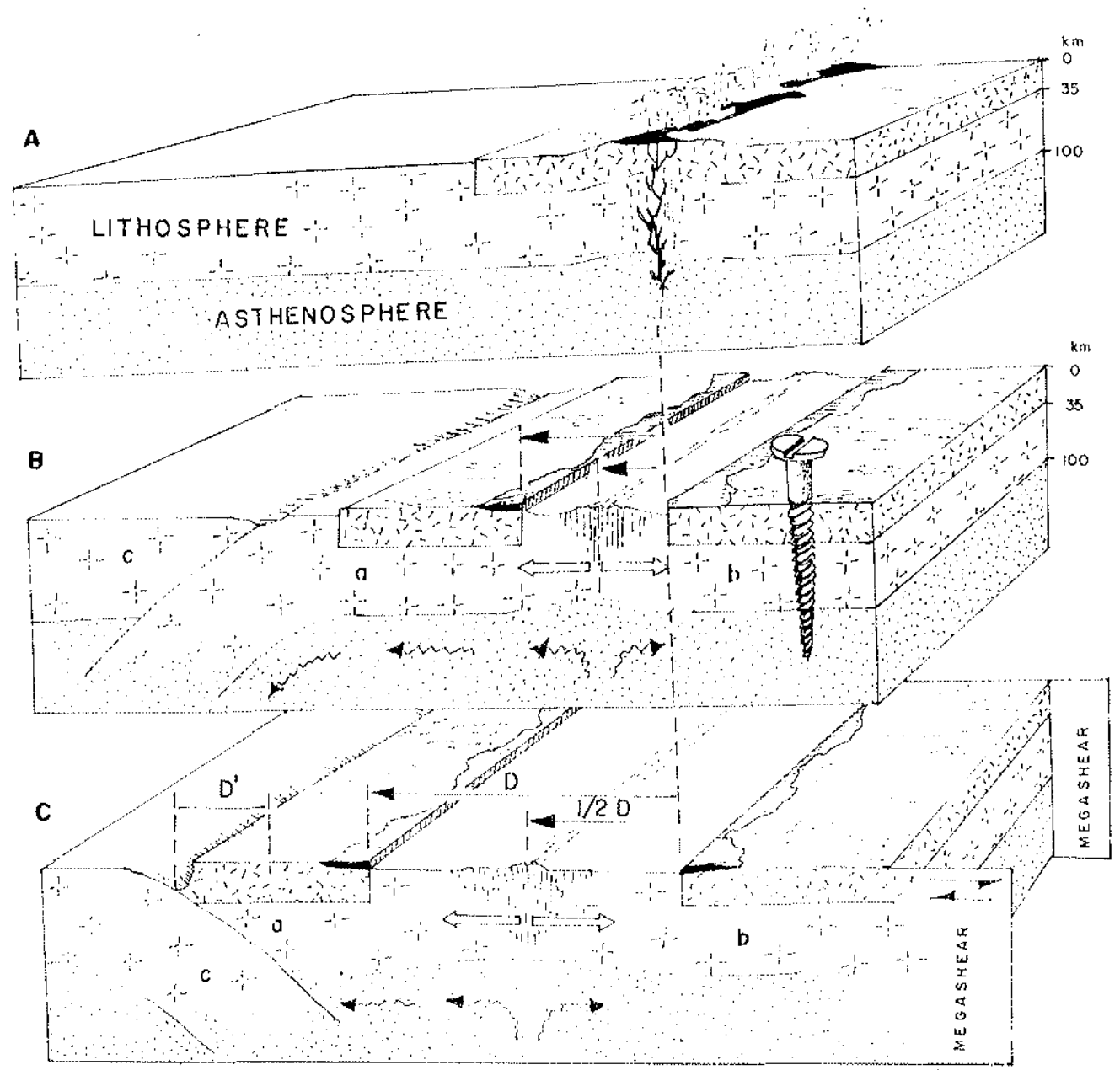

Figura 2 - Aspectos principais da tectônica de placas (Dietz e Holden, 1970)

1) O magma se eleva a partir do manto, preenchendo a zona central da cadeia oceânica, e os diques de lava expelem uma emissão de basalto.

2) A expansão resultante produz uma nova bacia oceânica, formando uma cadeia médio-oceânica. Esta deve sua posição à formação simétrica de uma nova crosta oceânica, em função da expansão dos pisos oceânicos. A placa a move-se no sentido oeste, até uma fossa, que é uma zona de absorção de placas.

3) À medida que a expansão prossegue, o continente em movimento chega até a fossa, porém nào c absorvido dentro do manto por ser flutuante. Depois o continente solurepassa a fossa e provavelmente mude a direção do mergulho da "zona de Benioff" dentro da fossa. Dessa forma, a placa $a$ deixa de ser uma placa em destruição e se transforma em uma placa em crescimento, às custas da placa $c$, que pode desaparecer.

Segundo os autores anteriormente citados, a superficie de nosso plancta pode ser dividida nas seguintes nove placas: África, América do Sul, América do Norte, Eurásia, Índia, Austrália, Pacífico Oriental, Pacífico Ocidental e Antártica. 
A deriva dos continentes $O$ conceito da deriva continental foi aventado por Wegener (1912), e considera todas as massas contiuentais agrupadas numa só, há várias centenas de milhões de anos. Posteriormente esse protocontinente se desmembrou, migrando os fragmentos até suas posições atuais. Essa idéia foi defendida por pouquíssimos cientistas há 20 anos atrás, sendo refutada ardorosamente pelas incoerências e falta de. explicação para certos aspectos que não podia proporcionar.

O fenômeno da expansão dos pisos oceânicos veio responder às principais objeções feitas à teoria de Wegener, e, ainda mais, veio comprovar os seus cálculos de tempo, elaborados somente com dados geológicos.

Posteriormente, com o advento do conceito das falhas transformais e da teoria da tectônica de placas, renovou-se o interesse sobre a deriva continental, tendo-se realizado grande número de pesquisas em todo mundo para comprovar sua validade, tanto no campo da geologia como no da geolisica. Atualmente a deriva dos continentes é um fenômeno comprovado e em desenvolvimento.

Dos trabalhos encetados para comprovar a deriva continental, menciona-se o de Dietz e Holden (1970), que elaboraram a reconstrução da Pangaea, sugerido por Wegener, ou seja, a massa continental única que existiu durante o Pérmico, há 225 m.a. (Fig. 3); operou-se essa reconstrução com os recursos de computador, baseando-se na melhor concordância fisiográfica das margens continentais e tendo-se como referência a cota isobática de 1000 braças. Nota-se, na Fig. 3, a coerência dos limites continentais, exceto por pequenas superposições (em preto) e por poucas discordâncias (em branco).

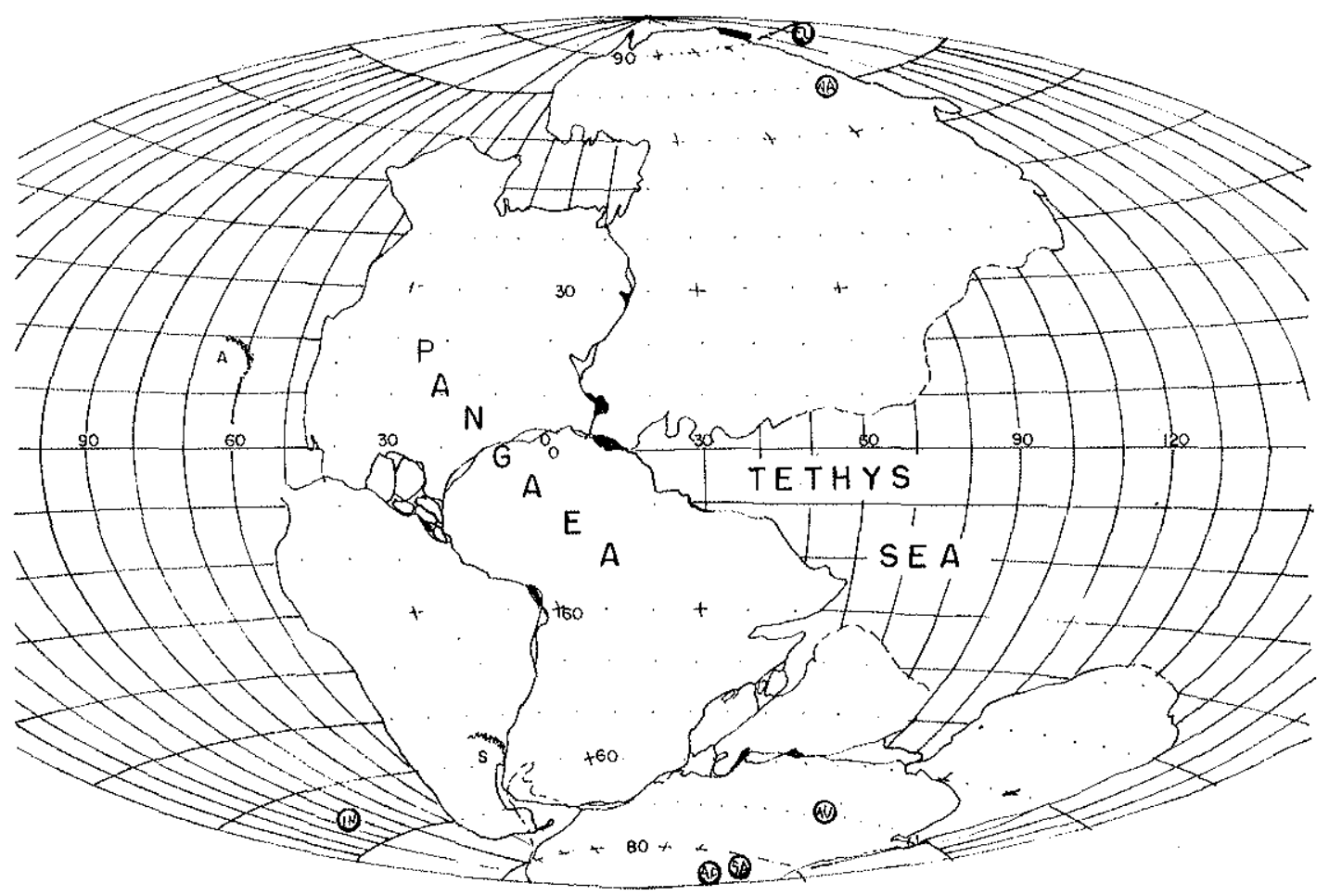

Figura 3 - Reconstrução dos continentes na massa universal Pangaea, 225 m.a. atrás (Dietz e Holden, 1970) 
Os arcos $A$ e $S$ da Fig. 3 correspondem a feições fisiográficas atuais, a que se prestam como referência o Arco das Antilhas e o Arco Scotia, respectivamente. Na Fig. 4, pode-se apreciar uma das várias etapas da reconstrução efetuada por Dietz e Holden (1970) correspondente desta feita ao fím do Cretáceo, após o início da deriva continental. Observa-se a grandeza dos movimentos relativos dos continentes, assim como o sentido dos mesmos e o volume dos derrames basálticos ocorridos durante o Gretáceo.

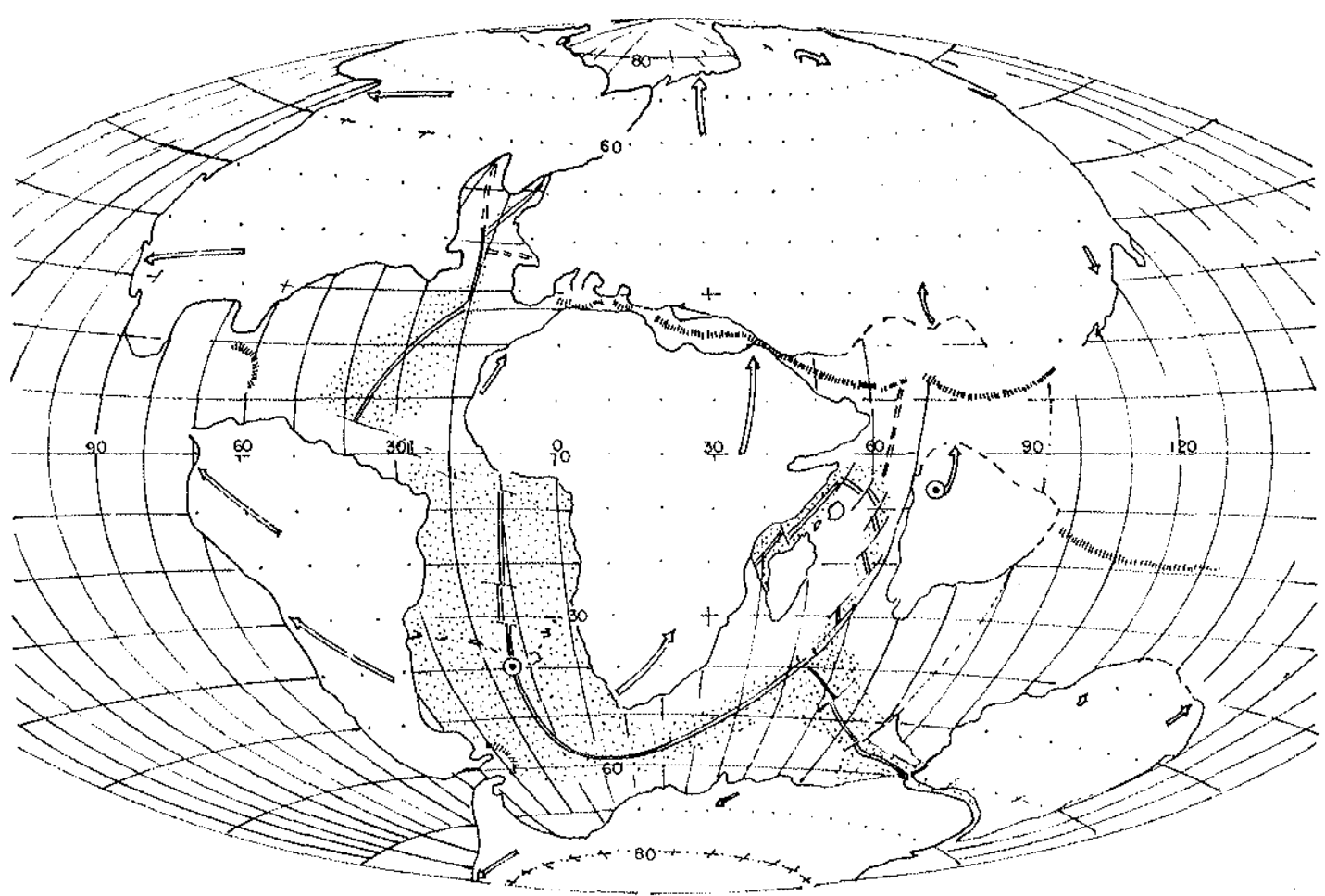

Figura 4-A deriva continental no Cretáceo, 65 m.a. atrás (Dietz e Holden, 1970)

O conceito da migração continental, juntamente com os fenômenos de tectônica de placas e da expansão dos pisos oceânicos constituem atualmente os temas mais impor. tantes, propiciadores dos estudos mais empolgantes sobre magnos problemas da geotectônica e da geodinâmica.

O presente trabalho fundamenta-se nos princípios estabelecidos a partir desses conceitos, considerando-se que o continente sul-americano translada-se no sentido NO, segundo pesquisas de Wilson (1965), como ilustrado nas Figs. 1 e 5, onde se observam as falhas transformais, definidas também por esse autor (1965), de ordem continental e de acordo com os estudos de Loczy (1970).

Amplitude e magnitude sísmicas DISTRIBUIÇÃO DA AMPLITUDE COM A DISTÂNCIA Via de regra, a amplitude sísmica decresce com a distância epicentral; entretanto esse decréscimo não é uniforme, como se pode apreciar no gráfico da Fig. 6 (Jordan et al., 1968). 
$60^{\circ} \mathrm{w}$

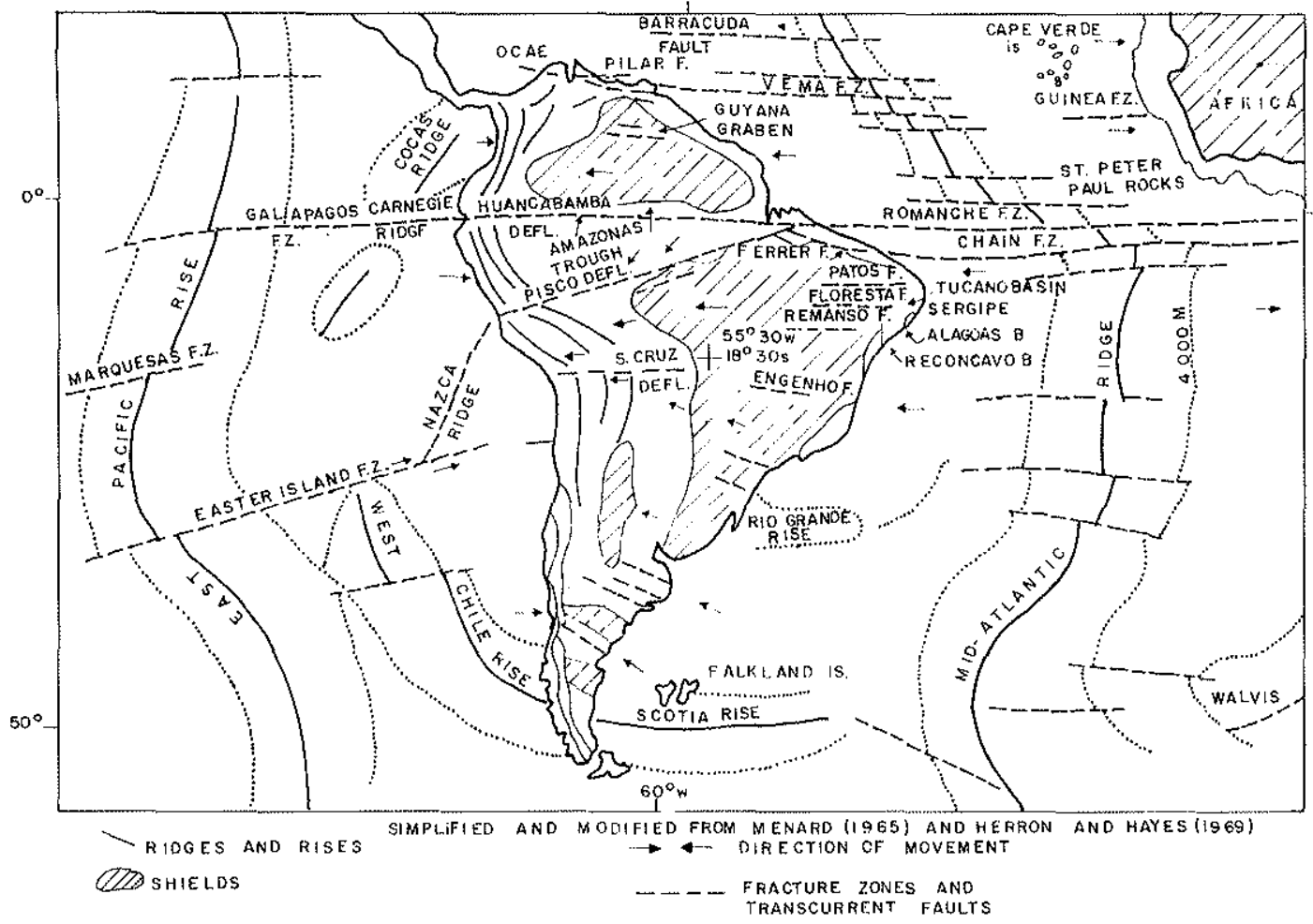

Figura 5 - Diagrama generalizado das principais falhas transcorrentes na América do Sul e suas relaçóes genéticas com zonas de fratura da cadeia médio-oceânica. Modificado de De Loczy (1969). Segundo De Loczy (1970)

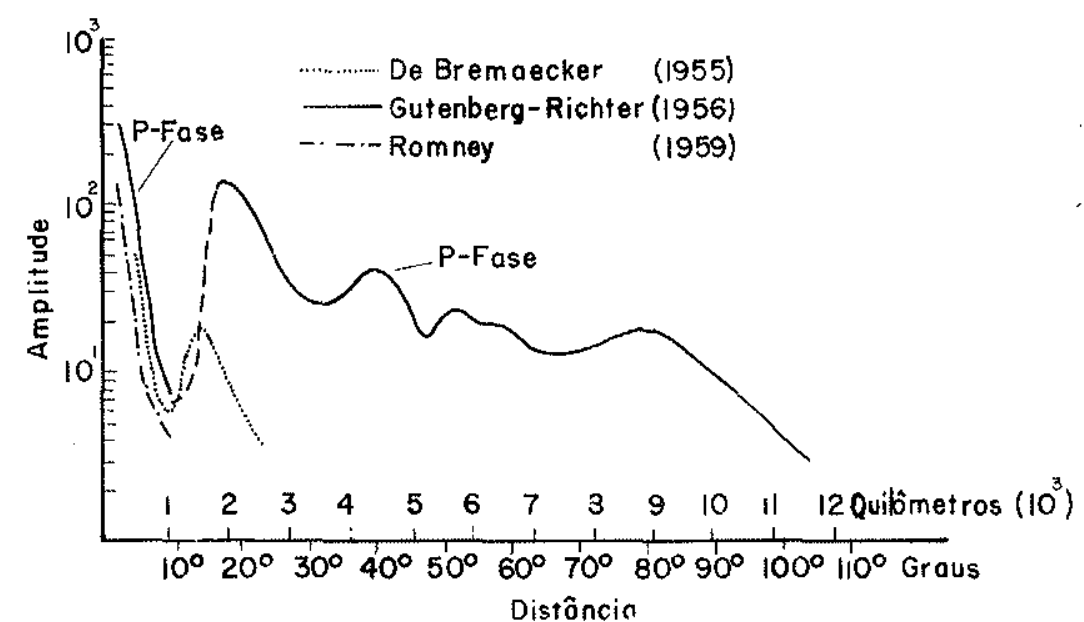

Figura 6-Dados selecionados de amplitudenatenuação de ondas Pn e P. Segundo Jordan, Black e Bates (1968) 
A curva de distribuição da amplitude com a distância epicentral é muito irregular; não obstante, é possível distinguir as seguintes particularidades:

a) entre $12^{\circ}$ e $18^{\circ}$ de distância epicentral ocorre uma anomalia provocada pela camada de baixa velocidade existente no manto e que corresponde à astenosfera, descrita anteriormente;

b) a partir de $18^{\circ}$ de distância, as amplitudes tornam-se maiores, crescendo anomalamente no sentido positivo, a cerca de $40^{\circ}$ de distância epicentral.

Considerando o exposto, não é de esperar que se encontrem anomalias negativas após $18^{\circ}$ de distância. Cumpre salientar aqui que os sismos ocorridos ao norte da Bacia Amazônica, a partir dos quais os autores inferem a existência de uma anomalia sísmica, possuem suas distâncias epicentrais superiores a $18^{\circ}$.

CÁLCULO DA MAGNITUDE A magnitude de um sismo é uma medida absoluta, proporcional à energia por ele liberada. $O$ valor da magnitude deve ser o mesmo, independendo da diferente distribuição das estações sísmicas que o captam e a partir de cujos registros se elaboram os cálculos.

Usando as ondas longitudinais $(P)$ de um sismo, calcula-se a magnitude sísmica $(m)$ através da seguinte equação:

$$
m=Q+\log A-\log K T,
$$

onde

$Q$ constante dependente da distância epicentral e da profundidade focal,

$A$ amplitude máxima pico a pico da onda $P$ figurada no registro, em milímetros,

$T$ período da onda $P$, em segundos,

$K$ amplificação da estação, dada em milhares.

Por conseguinte, é possível, a partir da equação supracitada, calcular-se a amplitude teórica com a qual a onda $P$ deveria chegar em uma determinada estação. Para isso é necessário conhecer o valor $K$ da estação, a distância entre o epicentro e a estação, a profundidade do foco sísmico e o período da onda $P$ na estação (a partir de seus registros), assim como a magnitude do sismo; usa-se a seguinte fórmula:

$$
\log A=m-Q+\log K T \text {. }
$$

Observação da anomalia sísmica Desde o estágio experimental do SAAS, em novembro de 1966, tem-se observado que a estação não registra a maioria dos sismos sucedidos ao norte da Bacia Amazônica, i.e, na região compreendida pela Colômbia, Vénezuela, América Central, Caribe, México e Califórnia.

A elevadíssima capacidade de magnificação do SAAS e sua excelente e privilegiada posição geológica-geográfica permitem que se registre, em Brasília, a maior parte de sismos que ocorrem nos demais países da América do Sul e no Oceano Atlântico, bem como sismos ocorridos alem da zona de sombra (entre $105^{\circ}$ e $120^{\circ}$ ). O limite de captação do SAAS para ondas $P$ corresponde a sismos de magnitude inferior a $4^{\circ}$ na escala de Richter.

Por essa razão, a discrepância verificada no registro dos sismos ocorridos ao norte da Bacia Amazônica permitiu que se inferisse a existência de uma anomalia na trajetória desses eventos. Vários abalos sucedidos nessa região e detectados pelo SAAS foram investigados em detalhe, tendo-se encontrado que, em geral, as amplitudes teóricas desses sismos eram muito maiores que as observadas no registros do SAAS; ademais, constatou-se que tal diferença é menor à medida que a distância epicentral dos sismos aumenta. 
Na Fig. 7 apresentam-se três sismos, dois dos quais ocorridos ao norte da Bacia Amazônica e o outro no Peru. Calcularam-se as amplitudes teóricas dos mesmos, conforme o exposto em cálculo da magnitude. Para o sismo peruano, a amplitude teórica e a observada foram quase iguais. Para o abalo sucedido na América Central, verificou-se uma diferença enorme entre as amplitudes observada e teórica, enquanto que tal diferença, para o sismo do México, mostrou-se menor. Ambas as amplitudes relacionadas a estes dois últimos eventos são ilustradas na Fig. 7.

Logrou-se dessa forma estabelecer a existência de uma anomalia na amplitude dos sismos ocorridos ao norte da Bacia Amazônica e registrados pelo SAAS.
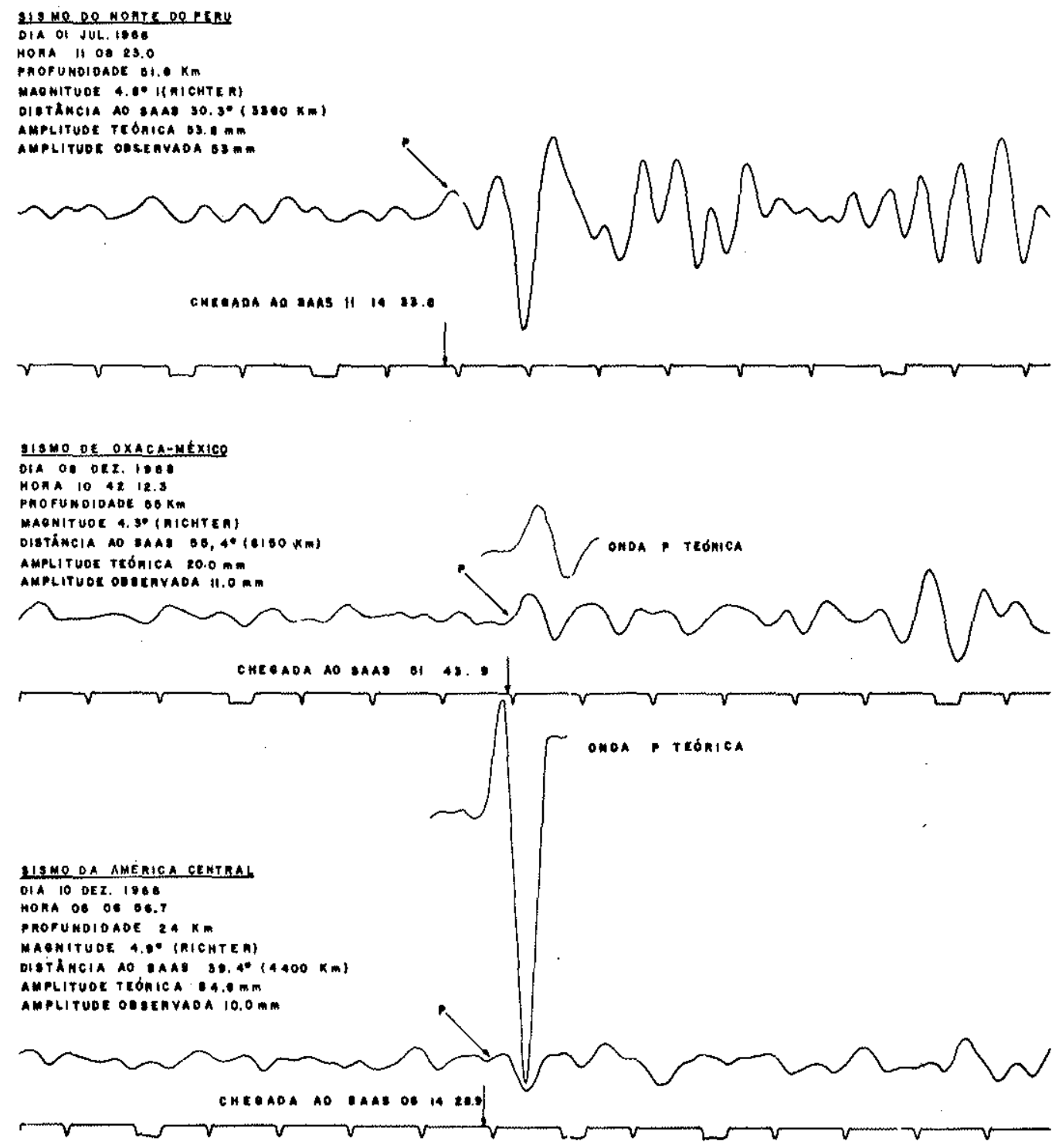

Figura 7 - Exemplos de eventos (sismos) registrados pelo SAAS empregados para mostrar a existêncía da anomalia sísmica na amplitude dos abalos ocorridos ao norte da Bacia Amazônica 
Possiveis causas da anomalia sísmica Podem-se anotar como possíveis causas da anomalia observada, as seguintes:

a) irregularidade estrutural da região focal;

b) irregularidade estrutural no substrato da ESB;

c) descontinuidades na trajetória das ondas sísmicas.

A primeira possível causa da anomalia pode ser eliminada já que os sismos ocorridos ao norte da Bacia Amazônica foram registrados por outras estações do globo, que apresentaram as amplitudes sísmicas concordantes com a magnitude dos eventos. Logo, não existem irregularidades na estrutura da região focal, desses eventos.

Do mesmo modo, pode-se rejeitar a segunda possível causa da anomalia, ou seja, a existência de alguma irregularidade no substrato da estação, uma vez que sismos de outros azimutes são detectados pelo SAAS com suas amplitudes esperadas, conforme ilustra a Fig. 7 para o sismo do Peru.

Resta então a terceira possibilidade como causa da anomalia nas amplitudes dos sismos ocorridos ao norte da Bacia Amazônica registradas pelo SAAS. Analisando-se as descontinuidades que a trajetória desses sismos podem interceptar, temos:

a) interferência dos estratos da crosta terrestre;

b) interferência da camada de baixa velocidade do manto superior (astenosfera);

c) interferência de alguma outra descontinuidade na constituição do manto terrestre.

A interferência provocada pelos estratos da crosta terrestre é, sobretudo, observada nos sismos locais, até $1000 \mathrm{~km}$ de distância epicentral, em cujos registros aparecem diferentes fases da onda $P$, de acordo com estratos atravessados pelas ondas sísmicas. Por esse motivo, as amplitudes desses sismos não são tão grandes como deveriam, e diminuem rapidamente à medida que se afastam do epicentro (Fig. 6).

A interferência causada pela camada de baixa velocidade, constituída pela astenosfera da Fig. 2, é verificada nos sismos com distâncias epicentrais entre 1000 e $2000 \mathrm{~km}$ (Fig. 6). Essa camada canaliza parte da onda $P$ e outra parte é refletida ou refratada, causando, portanto, uma fragmentação da energia carregada pela onda $P$; tal fragmentação, por sua vez, origina uma confusão no registro obtido desses sismos, com a quantidade de fases $P$ que chega mais ou menos simultaneamente à estação. Como se vê na Fig. 6, essa des. continuidade afeta só os sismos entre 1000 e $2000 \mathrm{~km}$ de distância epicentral; a partir de $2000 \mathrm{~km}$ as amplitudes decrescem gradativamente até os $9000 \mathrm{~km}$, notando-se uma anomalia positiva entre 4000 e $5000 \mathrm{~km}$ de distância, conforme acima exposto.

Vê-se pois, que nenhuma das descontinuidades anteriores poderia afetar as ondas dos eventos ocorridos na parte norte da Bacia Amazônica, já que as distâncias epicentrais desses eventos são maiores que $3000 \mathrm{~km}$.

Resta assim, como explicação, a existência de alguma irregularidade na constituição do manto terrestre como causadora da anomalia sísmica observada no SAAS. Tal irregularidade constitui uma anomalia tectônica, a qual será estudada mais detalhadamente como parte do programa de projetos da $\mathrm{UnB}$, durante o Projeto Geodinâmica.

Separação dos escudos das Guianas e Brasileiro Examinando-se as características fisiográficas superficiais da região compreendida entre Brasília e México, nota-se que a feição mais expressiva, além da presença dos Andes, é a existência dos escudos das Guianas e Brasileiro.

Fazendo-se uma reconstrução teórica das trajetórias das ondas dos sismos da América Central e do México (Fig. 7) em sua viagem até a ESB, constata-se que elas passam a 500 
e $700 \mathrm{~km}$ de profundidade, respectivamente, sob a Bacia Amazônica. Deve-se lembrar, outrossim, que o sismo do México foi menos afetado em sua amplitude que o da América Central, que passa a menor profundidade por baixo da Bacia Amazônica.

Os argumentos anteriores, juntamente com a evidência superficial da individualização dos escudos das Guianas e Brasileiro, induzem a inferir que existe uma diferenciação vertical na estrutura interna da Terra, até uma profundidade maior que $700 \mathrm{~km}$, que se prolonga a partir da Bacia Amazônica (Fig. 8). Essa diferenciação vertical na estrutura do manto terrestre poderia, portanto, ser a causa da anomalia sísmica observada pela ESB.

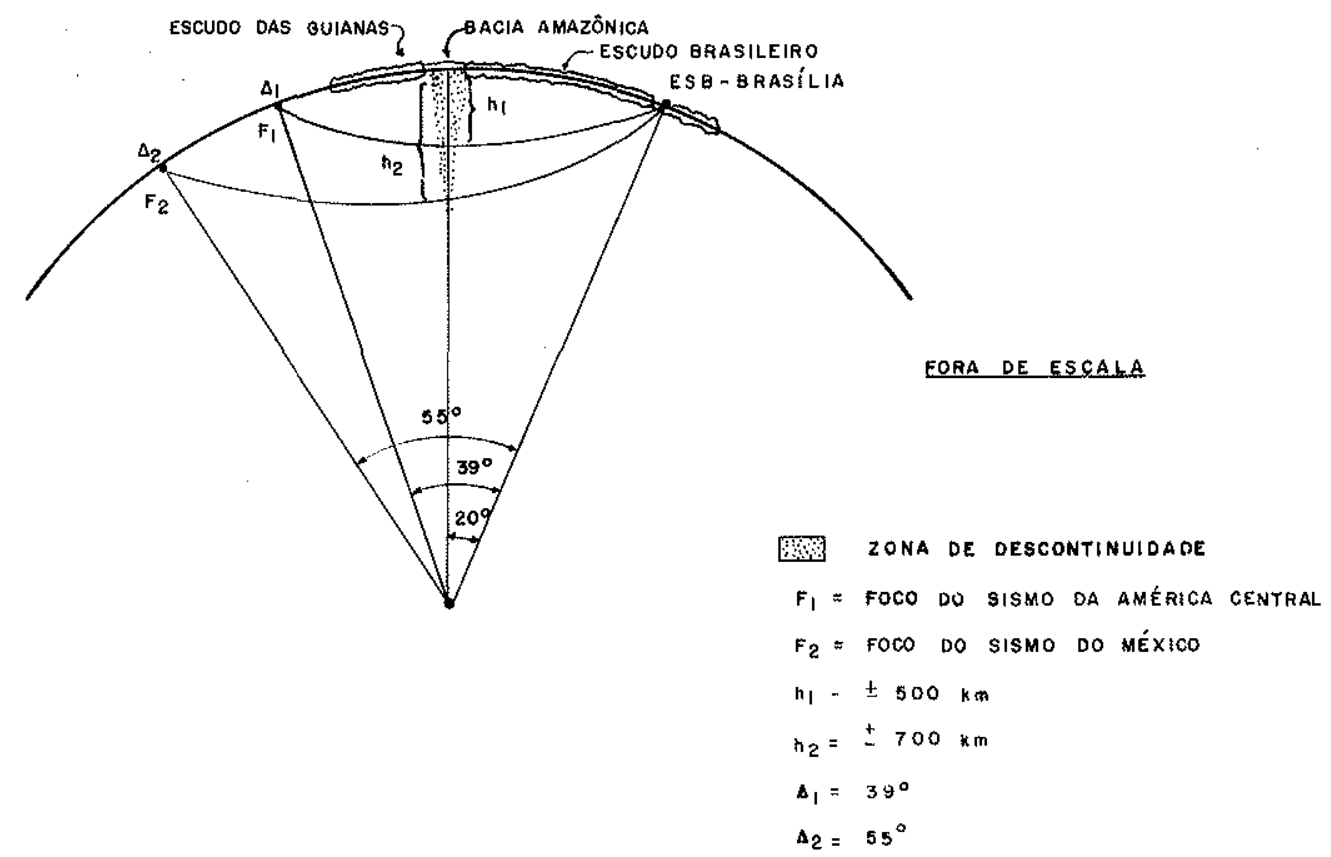

Figura 8 - Esquema ilustrando a hipótese da descontinuidade sob a Bacia Amazônica, que se aprofunda no manto terrestre até além de $700 \mathrm{~km}$, para mostrar a anomalia sísmica detectada pela ESB

Desse modo, poder-se-ia então confirmar o colapso físico dos escudos das Guianas e Brasileiro o qual poderia ter-se sucedido segundo o esquema apresentado na Fig. 9.

Loczy (1970) sugeriu que a Bacia Amazônica teria resultado da desagregação de um único pretérito escudo Guiana-Brasileiro resultante do movimento diferencial relativo para oeste dos dois escudos, segundo a Fig. 5 apresentada pelo referido autor.

Guimarães (1971) oferece outra interpretação da separação dos escudos sul-americanos, sugerindo uma rotação dos mesmos e a existência de um mar continutulal que lommou os sedimentos da Bacia Amazônica desde antes da era mesozóica.

De qualquer modo, vemos que a separação física dos principais escudos de nosso continente é um fato sugerido também por outros autores, embora suas conclusões se fundamentem $\mathrm{em}$ dados geológicos superficiais, do ponto de vista da geofísica.

CONCLUSÓES A anomalia sísmica observada nos registros da ESB, que acusa uma amplitude menor para os sismos ocorridos ao norte da Bacia Amazônica, é, possivelmente, provocada por uma anomalia tectônica na constituição interna da Terra, e que se projeta sob a Bacia Amazônica estendendo-se além dos $700 \mathrm{~km}$ de profundidade. 


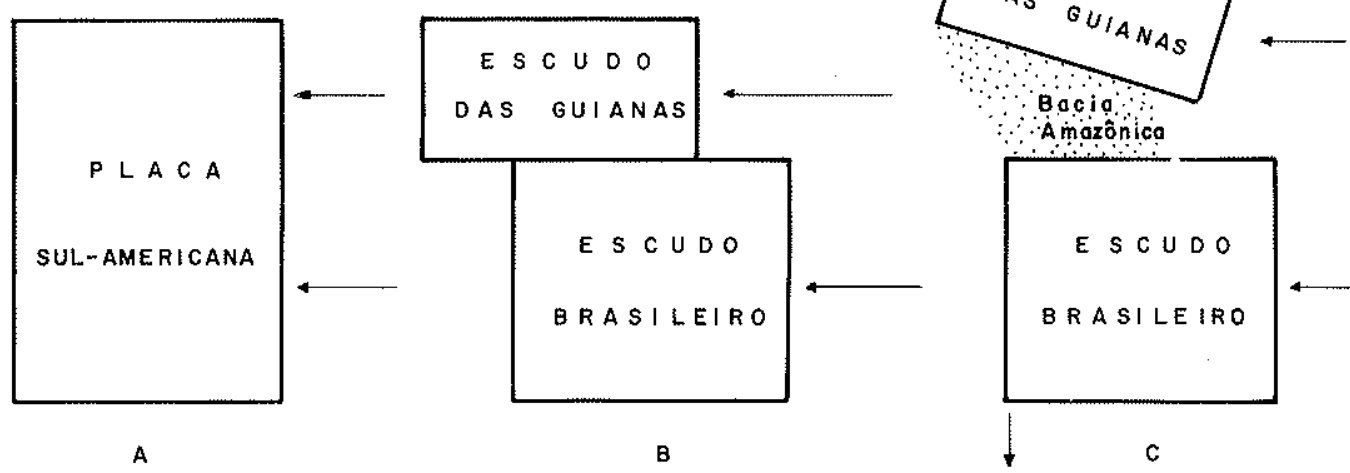

Figura 9 - Esquema ilustrando a hipótese da gênese da Bacia Amazônica, com base na anomalia sísmica registrada pelo SAAS (Brasília) e na teoria das placas continentais

A - Placa sul-americana antes do rompimento

B - Escudo das Guianas e Brasileiro deslocados na direção O-E pelo sistema de falhas Romanche-Galopagos-Chain

C - Deslocamento na direção N-S do escudo das Guianas e Brasileiro com a formação da Bacia Amazônica

É conclusiva, também, a existếncia da separação fisica dos escudos das Guianas e Brasileiro a qual propiciou a geração da Bacia Amazônica, fenômeno esse que, possivelmente, continue em nossos dias seguindo o mecanismo da deriva continental, porém com uma escala muitíssimo menor.

Evidências que suportam as conclusões 1) A existência da anomalia sísmica observada pelo SAAS, isto é, amplitudes menores que sugerem uma perda de energia na trajetória dos sismos ocorridos ao norte da Bacia Amazônica.

2) A existência da Bacia Amazônica, cujos sedimentos são relativamente modernos (Cretáceo superior ao Mioceno), segundo Lcinz e Amaral (1969).

3) A ocorrência de abalos sísmicos com epicentros na Bacia Amazônica (Manaus e Belém).

4) A existência de uma notável anomalia gravimétrica positiva na parte central da Bacia Amazônica, obtida durante os levantamentos exploratórios feitos pela Petrobrás.

5) A ocorrência de sismos nos Andes da Colômbia e Venezuela.

6) Os resíduos positivos em tempo para sismos ocorridos ao norte da Bacia Amazônica e registrados na ESB, o que sugere um retardo das ondas sísmicas antes de chegarem à estação.

\section{BIBLIOGRAFIA}

DALY, R. A. - 1940 - Strength and Structure of the Earth, Prentice-Hall, Englewood Cliffs, N. J. DIETZ, R.S. - 196l - Continent and Ocean Basin Evolution by Spreading of the Sea Floor, Nature, 190: 854

DIETZ, R.S., e HOLDEN J. C. - 1970 - Reconstruction of Pangaca: Breakup and Dispersion of Continents, Permian to Present, J. Geophys. Res., 75 (26): 4939

GUIMARÃES, D. - 1971 - Gênese da Bacia Amazônica, Notas Preliminares e Estudos, DNPM, 149 
HEIRT/I.ER, J. R., DICKSON, G. O. HERRON, E. M. PITMAN, W. G. E LE PIGHON X. - 1968 - Marine Magnetic Anomalies, Geomagnetic Field Reversals, and Motions of the Ocean Floor and Continents, J. Geophys. Res., 73 (6): 2119

HESS, H. H. - 1962 - History of the Ocean Basins, in Petrological Studies: A Volume in Honor of A. F. Buddington, editado por A. E. J. Engel et al., p. 599, Geological Society of America, New York

ISACKS, B., OLIVER, J. e SYKES L. R. - 1968 - Sismolugy and the Xiw Global Tectonics, J. Geophys. Res., 73 (18): 5855

JORDAN, J.N., BLACK R.A. c BATES CH.C. - 1968 - Patterns of Maximum Amplitudes of $P n$ and $P$ Waves over Regional and Continental Areas, Procedings of the Eighth Assembly of the European Seismological Commission, Budapest

LEINZ, V., c AMARAL S. L. do - 1969 - Geologia Geral, Gompanhia lidincra Niacional, São Paulo

LE PICHON, X. - 1968 - Sea-Floor Spreading and Continental Drift, J. Geophys. Res., 73 (12): 3661

LE PICHON, X., c HEIRT\%LER J. R. - 1968 - Magnetic Anomalies in the Indian Oecin and Sea-Floor Spreading, J. Geophys. Res., 73 (1): 210

LOCZY, L. DE - 1970 - Role of Transcurrent Faulting in South America Tectonic Framenork, American Association of Petroleum Geologists Bull, 54 (11)

MORGAN, W. J. - 1968 - Rises, Trenches, Great Faults, and Crustal Blocks, J. Geophys. Res., 73 (6): 1959

PITMAN, W., C HAYES D. - 1968 - Sea-Floor Spreading in the Gulf of Alaskia, J. Gopplyys. Res., 73 (20): 657 !

SYKES, L. - 1967 - Mechanism of Earthquakes and Nature of Faulting in the Mid-Oceanic Ridges, J. Geophys. Res., 72: 2131

VINE, F.J., e MATTHEWS D.H. - 1963 - Magnetic Anomalies Over Ocan Ridges, Nature, 199: 947

WEGENER, A. - 1912 - The Origin of Continents and Occans, Dover, New York

WILSON, J. T. - 1965 - Submarine Frature Zones, Aseismic Ridges, and the ICSU Line: Proposed Western Margin of the East Pacific Ridge, Nature, 207: 907 